\title{
Out-of-Pocket Costs of Asthma Follow-Up Care in Adults in a Sub-Saharan African Country
}

\section{Cajetan Chigozie Onyedum, ${ }^{1}$ Olufemi Olumuyiwa Desalu, ${ }^{2}$ Kingsley Nnanna Ukwaja, ${ }^{3}$ Chinwe Chukwuka, ${ }^{1}$ Nnamdi Ikechukwu Nwosu, ${ }^{4}$ and Chijioke Ezeudo ${ }^{5}$}

\author{
${ }^{1}$ Department of Medicine, College of Medicine, University of Nigeria, Enugu Campus, Enugu 400241, Nigeria \\ ${ }^{2}$ Department of Medicine, College of Health Sciences, University of Ilorin, Ilorin 240213, Nigeria \\ ${ }^{3}$ Department of Internal Medicine, Federal Teaching Hospital, Ebonyi State, Abakaliki 480281, Nigeria \\ ${ }^{4}$ Department of Medicine, University of Nigeria Teaching Hospital, Ituku Ozalla, Enugu 400228, Nigeria \\ ${ }^{5}$ Medical Division, Nigerian Ports Authority PLC, Lagos 101251, Nigeria
}

Correspondence should be addressed to Kingsley Nnanna Ukwaja; ukwajakingsley@yahoo.co.uk

Received 4 January 2014; Revised 2 March 2014; Accepted 3 March 2014; Published 31 March 2014

Academic Editor: Umesh Yadav

\begin{abstract}
Copyright (C) 2014 Cajetan Chigozie Onyedum et al. This is an open access article distributed under the Creative Commons Attribution License, which permits unrestricted use, distribution, and reproduction in any medium, provided the original work is properly cited.
\end{abstract}

\begin{abstract}
Asthma care imposes economic burden on affected patients. Patient costs for asthma care have not been documented in Africa. We aimed to determine the out-of-pocket cost of asthma follow-up care incurred by patients in Nigeria. We conducted a crosssectional study in three tertiary hospitals in southeastern and northwestern Nigeria. Poorly controlled asthma patients attending a follow-up visit in the respiratory clinic of the hospitals were surveyed. Sociodemographic, health-seeking behavior, and cost data were collected using a structured questionnaire. Of the 110 patients who completed the study, 56 (51\%) were females. Also, $72(65 \%)$ of the patients had known about their asthma illness for more than four years. Mean annual direct cost of asthma care was US $\$ 368.4( \pm 228)$ per patient. Medication cost accounted for the majority $(87 \%)$ of this cost. Patient costs of care incurred did not differ significantly across age $(P=0.15)$, education $(P=0.23)$, marital status $(0.49)$, residence $(P=0.47)$, or gender $(P=$ $0.65)$ categories. We conclude that direct cost of care was found to be substantial among poorly controlled asthma patients. Further studies to estimate the costs incurred by patients with exacerbation and differing severity of the disease should be conducted.
\end{abstract}

\section{Introduction}

Bronchial asthma is a common chronic respiratory disease worldwide [1]. According to the Global Initiative for Asthma (GINA), it affects $5.4 \%$ of adults in Nigeria, and its prevalence is increasing [1-3]. A recent study showed a low level of asthma control among adult asthmatics in Nigeria [4]. Poorly controlled asthma imposes a substantial economic impact on the patient and health system, primarily through direct costs from followup, hospitalization, and medications and indirect costs from lost productivity $[5,6]$.

A previous study showed that the cost of regular treatment of chronic diseases including asthma is unaffordable to families in low-resource settings $[7,8]$. This results in a considerable high proportion of uncontrolled asthma, which is associated with greater economic burden to families and the health system and deterioration in quality of life [7-9]. In high-/middle-income countries, costs of asthma inpatient care [10], hospitalization [10-12], and exacerbations [13] have been previously documented. However, reports on cost of asthma followup among individuals with poorly controlled asthma are lacking worldwide.

Furthermore, no data exists on the economic impact of asthma care on patients in Africa. In a recent systematic review, no single study from the region was found [14]. In Nigeria, $83-92 \%$ of asthma patients have poorly controlled asthma, and poor adherence to medications has been identified as one of the factors responsible for it $[4,15]$. It is likely that high cost of asthma care may be contributory to the poor adherence observed. Therefore, there is need to evaluate if patient costs of asthma care are a major issue in our setting. 
Moreover, understanding patients' cost of asthma follow-up visit may assist with clinical management decisions. This feasibility study aimed to determine the direct cost of adult asthma follow-up care from the patients' perspective in Nigeria.

\section{Materials and Methods}

2.1. Study Setting. The study was conducted in three tertiary hospitals in Nigeria. The study sites include the University of Nigeria Teaching Hospital (UNTH), Ituku Ozalla, Enugu, Ebonyi State University Teaching Hospital, Abakaliki (EBSUTH), located in southeastern Nigeria, and the University of Ilorin Teaching hospital (UITH) located in the northwestern part of the country. The hospitals offer primary, secondary, and tertiary health services and have at least two respiratory physicians per institution. Asthma care is provided by a team consisting of physicians, nurses, and pharmacists. During a follow-up visit, patients receive a prescription of their asthma medication. Medications prescribed depend on the asthma control status and included options like powdered or pressurized metered-dose inhaled corticosteroid (budesonide/fluticasone) and beta-2 bronchodilators, long- and short-acting (salmeterol/salbutamol) or their combinations [16].

2.2. Study Design. In a cross-sectional cost-of-illness study, asthma patients attending the outpatients' respiratory clinic of the study hospitals were screened for enrollment in the study. The inclusion criteria were (1) adult ( $>14$ years old) patients with asthma; (2) physician-diagnosed asthma with documented airway reversibility $(\geq 12 \%$ and a $200 \mathrm{~mL}$ increase in forced expiratory volume in 1 second $\left(\mathrm{FEV}_{1}\right)$ after inhaling $200 \mu \mathrm{g}$ salbutamol or $\geq 15 \%$ increase in FEV1 after treatment with asthma medication); (3) poorly controlled asthma according to GINA guidelines [16]. Patients with acute exacerbation requiring hospitalization; controlled asthma; comorbidities; and newly diagnosed asthma were excluded.

2.3. Assessment of Economic Costs. Direct costs of asthma followup were assessed using a pretested, structured interviewer-administered questionnaire designed by the investigators. All the patients were interviewed in their preferred language. Data collection took place from January to June 2011. The data collected included patient demographic information, healthseeking behavior, and costs of asthma-related care. Direct costs included medical (drugs, laboratory tests, and administrative) costs as well as the nonmedical (transportation) cost. Cost data were collected for all asthma-related care and treatment that had been given to the patient per month or in the last month preceding the study. All costs were recorded in 2011 US dollars (\$) (in 20111 US\$ = 160 Nigeria Naira).

2.4. Sample Size. A convenient sample size of 100 was adopted based on the number of adult patients that received treatment in the previous year with poorly controlled asthma at the participating hospitals - which ranged from 70 to 90 . In the six-month period of data collection, we anticipated that at least 150 eligible patients must have consulted the respiratory clinic of the participating hospitals. Also, we estimated a nonparticipation rate of $20 \%$ which necessitated increasing the sample size to 120 .

2.5. Data Analysis. Data obtained were entered and analysed using SPSS statistical software version 16 (SPSS Inc., Chicago, IL, USA). Sociodemographic characteristics and health-seeking behavior were presented using proportions (\%). Cost data were expressed as "mean \pm standard deviation (SD)." The normality of distribution of cost data was assessed using the Kolmogorov-Smirnov tests. Group comparisons of mean costs were done using Student's $t$-test. All $P$ values were bidirectional and values $<0.05$ were statistically significant.

2.6. Ethical Approval. The study was approved by the research and ethics committees of the University of Nigeria Teaching Hospital, Ituku Ozalla, Enugu, the Ebonyi State University Teaching Hospital, Abakaliki, and the University of Ilorin Teaching Hospital, Ilorin, Nigeria. An oral informed consent was obtained from all the included patients before the interview.

\section{Results}

3.1. Sociodemographic Characteristics of the Patients. The study surveyed 118 eligible patients. Full records were completed for 110 patients. Of this, 30 were from EBSUTH, 46 from UNTH, and 34 from UITH. The sample consisted of 54 (49\%) males and 56 (51\%) females; their mean age was $41.6 \pm$ 20.1 years, and 56 (51\%) of them were married (Table 1). The majority of them 94 (85\%) reside in an urban area, $82(75 \%)$ had at least six years of formal education and 34 (31\%) were civil servants (Table 1).

3.2. Asthma-Related Health-Seeking Behavior. About 72 (65\%) of the patients had known about their asthma illness for more than four years now, and 68 (62\%) claimed that they sought any care within one year of the onset of asthma symptoms (Table 2). The patients were referred to the asthma clinic in the respective hospitals either by a doctor (56 (51\%)) or other health workers $(18(16 \%))$. The majority of the patients $(88(80 \%))$ bought their asthma medications/inhaler from the hospital pharmacy where they sought care, and (90) $82 \%$ of them reported that their asthma drugs were always available in the hospital where they sought care (Table 2).

3.3. Costs of Asthma Care. The mean monthly direct cost of asthma care was US\$30.7 \pm 19 , mainly from drugs $\$ 26.7$, transportation $\$ 2.4$, and laboratory test $\$ 1.4$ (Table 3). Therefore, mean annual direct cost of asthma follow-up care was calculated as US\$368 $( \pm 228)$ per patient for 1 year. Medication costs (US\$320) accounted for the majority (87\%) of the mean annual cost of asthma follow-up care. The mean direct costs of asthma follow-up care incurred by the patients did not differ significantly across age $(P=0.15)$, education $(P=0.23)$, marital status $(0.49)$, residence $(P=0.47)$, or gender $(P=$ 0.65 ) categories (Table 4). 
TABLE 1: Sociodemographic characteristics of the respondents $(n=$ 110).

\begin{tabular}{lc}
\hline Variables & $N(\%)$ \\
\hline Age (years) & $58(53)$ \\
40 or less & $52(47)$ \\
$\quad$ More than 40 & \\
Gender & $56(51)$ \\
$\quad$ Female & $54(49)$ \\
Male & \\
Residence & $16(15)$ \\
Rural & $94(85)$ \\
Urban & \\
Formally educated ( $\geq 6$ years of education) & $82(75)$ \\
Yes & $28(25)$ \\
No & \\
Marital status & $62(56)$ \\
Married & $48(44)$ \\
Single & \\
Patient/head of household occupation & $10(9)$ \\
Farmer & $10(9)$ \\
Petty trading & $34(31)$ \\
Government worker & $12(11)$ \\
Employed in private sector & $8(7)$ \\
Big business & $10(9)$ \\
Self-employed professional & $26(24)$ \\
Other &
\end{tabular}

Furthermore, $70(63 \%)$ of the patients paid for their asthma follow-up care from their income while others reportedly paid for their asthma care through financial support received from their friends/relatives $(24(22 \%))$, through loans $(10(9 \%))$, or through community support $(2(2 \%))$. None of the patients' asthma follow-up care was covered by any form of health insurance scheme.

\section{Discussion}

In this study we have shown that irrespective of patients' sociodemographic characteristics, the mean annual direct cost of asthma follow-up care was US\$368 $( \pm 228)$ per patient and prescription costs accounted for $87 \%$ of this cost. The average asthma-related direct costs of care in developed countries ranged between \$273 in Australia, \$1779 in Switzerland, and up to $\$ 4101$ in the United States of America per patient annually $[5,17,18]$. In developing countries, average direct costs of asthma care per patient annually ranged between US $\$ 135$ in Thailand, US\$276 in Malaysia, and US $\$ 1,466$ in Turkey $[10,12,19]$. In the USA and Turkey, the total cost of asthma was estimated as US\$12.7 billion and US $\$ 1.9$ billion, in 1998 and 2004, respectively [10, 14]. Considering the midyear population count of 160 million [20] and the proportion of the population with clinical asthma in Nigeria (5.4\%) [1], our study suggests that, for Nigeria, the total cost of asthma care may also be substantial.
TABLE 2: Respondents' awareness of their asthma illness and careseeking behavior $(n=110)$.

\begin{tabular}{|c|c|}
\hline Variables & $N(\%)$ \\
\hline \multicolumn{2}{|c|}{ Duration of asthma illness (months) } \\
\hline$<12$ & $6(6)$ \\
\hline $13-24$ & $6(5)$ \\
\hline $25-36$ & $12(11)$ \\
\hline $37-48$ & $14(13)$ \\
\hline$>48$ & $72(65)$ \\
\hline \multicolumn{2}{|l|}{$\begin{array}{l}\text { Duration of asthma symptoms } \\
\text { before seeking care (months) }\end{array}$} \\
\hline$<12$ & $68(62)$ \\
\hline $13-24$ & $18(16)$ \\
\hline $25-36$ & $10(5)$ \\
\hline $37-48$ & $2(2)$ \\
\hline$>48$ & $22(20)$ \\
\hline \multicolumn{2}{|l|}{$\begin{array}{l}\text { Source of information/referral } \\
\text { to the asthma clinic }\end{array}$} \\
\hline Hospital staff & $14(12)$ \\
\hline Medical doctor referral & $56(51)$ \\
\hline Other health staff & $4(4)$ \\
\hline Friend & $4(4)$ \\
\hline Media & $12(11)$ \\
\hline Other & $12(11)$ \\
\hline Not aware of asthma clinic & $8(7)$ \\
\hline \multicolumn{2}{|l|}{$\begin{array}{l}\text { Duration of receiving asthma } \\
\text { treatment at the clinic (months) }\end{array}$} \\
\hline$<12$ & $32(29)$ \\
\hline $13-24$ & $10(9)$ \\
\hline $25-36$ & $14(13)$ \\
\hline $37-48$ & $6(5.5)$ \\
\hline$>48$ & $48(44)$ \\
\hline
\end{tabular}

Where do you normally buy your asthma medications/inhaler?

Hospital pharmacy

Open market/drug shops

Are the medications always available in your hospital?

Yes

No

The differences in the findings may be in part due to the socioeconomic environment where the study was conducted. For example, Nigeria has a gross national income of US\$1, 200 per capita compared with the United States where it is US\$41, 400 per capita [21]. Additional reasons may be due to differences in healthcare delivery system; for example, patients in Malaysia and Thailand [12,19] receive financial protection through government health insurance schemes which are currently at an early stage in Nigeria.

Medication cost accounted for the majority $(87 \%)$ of total direct expenditures in our study. This figure is similar 
TABLE 3: Patient monthly out-of-pocket expenditures for asthma care $(n=110)$.

\begin{tabular}{|c|c|c|c|}
\hline Variable & $\begin{array}{l}\text { Patients reporting } \\
\text { expenditure } N(\%)\end{array}$ & $\begin{array}{l}\text { Total costs incurred } \\
\text { by all patients (US\$) }\end{array}$ & Mean $( \pm$ SD) cost $(\mathrm{US} \$)$ \\
\hline \multicolumn{4}{|l|}{ Medical } \\
\hline Asthma drugs (inhalers) & $110(100 \%)$ & 1771 & $16.1( \pm 3.7)$ \\
\hline Other drugs & $110(100 \%)$ & 1166 & $10.6( \pm 2.2)$ \\
\hline Laboratory tests including X-ray & $110(100 \%)$ & 176 & $1.6( \pm 1.2)$ \\
\hline \multicolumn{4}{|l|}{ Nonmedical } \\
\hline Transportation (to and fro) & $110(100 \%)$ & 264 & $2.4( \pm 1.4)$ \\
\hline Average monthly cost per patient & & & $30.7( \pm 19)$ \\
\hline
\end{tabular}

All costs in 2011 US dollars: US\$; SD: standard deviation.

TABLE 4: Sociodemographic determinants of direct monthly patient cost of asthma care $(n=110)$.

\begin{tabular}{|c|c|c|c|}
\hline Variables & Mean $( \pm S D)$ cost & $t$-test & $P$ value \\
\hline \multicolumn{4}{|l|}{ Age (years) } \\
\hline 40 or less & $27.3 \pm 20.1$ & \multirow{2}{*}{2.10} & \multirow{2}{*}{0.15} \\
\hline More than 40 & $34.7 \pm 17.1$ & & \\
\hline \multicolumn{4}{|l|}{ Gender } \\
\hline Female & $29.6 \pm 18$ & \multirow{2}{*}{0.21} & \multirow{2}{*}{0.65} \\
\hline Male & $31.9 \pm 20.2$ & & \\
\hline \multicolumn{4}{|l|}{ Residence } \\
\hline Rural & $35.2 \pm 28.3$ & \multirow{2}{*}{0.52} & \multirow{2}{*}{0.47} \\
\hline Urban & $29.9 \pm 17.2$ & & \\
\hline \multicolumn{4}{|l|}{ Formally educated } \\
\hline Yes & $29 \pm 24.2$ & \multirow{2}{*}{1.35} & \multirow{2}{*}{0.23} \\
\hline No & $36.3 \pm 21.9$ & & \\
\hline \multicolumn{4}{|l|}{ Marital status } \\
\hline Married & $28.8 \pm 19.2$ & \multirow{2}{*}{0.48} & \multirow{2}{*}{0.49} \\
\hline Single & $32.5 \pm 52.5$ & & \\
\hline
\end{tabular}

SD: standard deviation.

to the $81 \%, 84 \%$, and $89 \%$ found in Turkey, Germany, and Australia, respectively $[10,16,22]$, but higher than other studies which reported that medication costs corresponded to a range between 30 and $47 \%$ direct costs of asthma care [1214]. The differences in prescription costs noted may be due to differences in the types of medication given to the patients, doses of medication required by each patient, and the severity of their asthma. Furthermore, lower cost of laboratory tests and consultations in developing countries compared with developed countries might have accounted for the lower treatment costs observed in our setting [8-14].

Also, we have shown that costs of follow-up care for asthma patients did not differ significantly across age, education, marital status, residence, or gender categories. This suggests that these sociodemographic characteristics of the patients did not affect the costs incurred by the patients for asthma follow-up care.

There are limitations in this study. The direct costs estimated in this study are an underestimate of the patient economic burden of asthma in Nigeria because indirect costs of asthma were not evaluated. Indirect costs have been shown to account for up to $50 \%$ of total costs of asthma-related treatment in some studies [14]. Also, cost data were obtained from the patients; this is subject to a potential recall bias. Despite these limitations, this feasibility study has shown that the direct cost of asthma followup is substantial and may be a contributor to the poor adherence to medication among asthma patients leading to poor adult asthma control in Nigeria. There is a need for a nationwide detailed assessment of the cost of treatment for asthmatics including those with poor/good control, complications, and exacerbation in Nigeria and other African countries. The findings of these assessments will determine the financial resources required and ensure that households of asthmatic patients are relieved from the potentially catastrophic costs of this illness. Furthermore, because prescription costs accounted for the majority of direct costs in this study, a cost-effectiveness analysis is needed to ensure effective treatment of asthma with optimal costs.

\section{Conflict of Interests}

The authors confirm that they have no conflict of interests to declare. 


\section{Acknowledgment}

The authors are thankful to all the patients who consented and participated in the study.

\section{References}

[1] M. Masoli, D. Fabian, S. Holt, and R. Beasley, "The global burden of asthma: executive summary of the GINA Dissemination Committee Report," Allergy, vol. 59, no. 5, pp. 469-478, 2004.

[2] G. Erhabor, S. Agbroko, P. Bamigboye, and O. Awopeju, "Prevalence of asthma symptoms among university students 15 to 35 years of age in Obafemi Awolowo University, Ile-Ife, Osun State," Journal of Asthma, vol. 43, no. 2, pp. 161-164, 2006.

[3] M. I. Asher, S. Montefort, B. Björkstén et al., "Worldwide time trends in the prevalence of symptoms of asthma, allergic rhinoconjunctivitis, and eczema in childhood: ISAAC Phases One and Three repeat multicountry cross-sectional surveys," The Lancet, vol. 368, no. 9537, pp. 733-743, 2006.

[4] O. O. Desalu, A. E. Fawibe, and A. K. Salami, "Assessment of the level of asthma control among adult patients in two tertiary care centers in Nigeria," Journal of Asthma, vol. 49, no. 7, pp. 765-772, 2012.

[5] T. D. Szucs, H. Anderhub, and M. Rutishauser, "The economic burden of asthma: direct and indirect costs in Switzerland," European Respiratory Journal, vol. 13, no. 2, pp. 281-286, 1999.

[6] S. Accordini, M. Bugiani, W. Arossa et al., "Poor control increases the economic cost of asthma: a multicentre populationbased study," International Archives of Allergy and Immunology, vol. 141, no. 2, pp. 189-198, 2006.

[7] A. A. Cruz and P. J. Bousquet, "The unbearable cost of severe asthma in underprivileged populations," Allergy, vol. 64, no. 3, pp. 319-321, 2009.

[8] S. Mendis, K. Fukino, A. Cameron et al., "The availability and affordability of selected essential medicines for chronic diseases in six low- and middle-income countries," Bulletin of the World Health Organization, vol. 85, no. 4, pp. 279-288, 2007.

[9] R. Franco, H. F. Nascimento, A. A. Cruz et al., "The economic impact of severe asthma to low-income families," Allergy, vol. 64, no. 3, pp. 478-483, 2009.

[10] G. E. Çelik, S. Bavbek, G. Paşaoǧlu et al., "Direct medical cost of asthma in Ankara, Turkey," Respiration, vol. 71, no. 6, pp. 587593, 2004.

[11] S.-H. Kim, T.-W. Kim, J.-W. Kwon et al., "Economic costs for adult asthmatics according to severity and control status in Korean tertiary hospitals," Journal of Asthma, vol. 49, no. 3, pp. 303-309, 2012.

[12] K. Chuesakoolvanich, "Cost of hospitalizing asthma patients in a regional hospital in Thailand," Respirology, vol. 12, no. 3, pp. 433-438, 2007.

[13] S. Bavbek, D. Mungan, H. Türktaş, Z. Misirligil, and B. Gemicioğlu, "A cost-of-illness study estimating the direct cost per asthma exacerbation in Turkey," Respiratory Medicine, vol. 105, no. 4, pp. 541-548, 2011.

[14] K. Bahadori, M. M. Doyle-Waters, C. Marra et al., "Economic burden of asthma: a systematic review," BMC Pulmonary Medicine, vol. 9, article 24, 2009.

[15] C. C. Onyedum, K. N. Ukwaja, O. O. Desalu, and C. Ezeudo, "Challenges in the management of bronchial asthma among adults in Nigeria: a systematic review," Annals of Medical and Health Sciences Research, vol. 3, no. 3, pp. 324-329, 2013.
[16] Global Initiativa for Asthma (GINA). Global strategy for asthma management and prevention. Vancouver: GINA, 2006, http://www.ginasthma.org.

[17] C. M. Mellis, J. K. Peat, A. E. Bauman, and A. J. Woolcock, "The cost of asthma in New South Wales," Medical Journal of Australia, vol. 155, no. 8, pp. 522-528, 1991.

[18] M. G. Cisternas, P. D. Blanc, I. H. Yen et al., "A comprehensive study of the direct and indirect costs of adult asthma," Journal of Allergy and Clinical Immunology, vol. 111, no. 6, pp. 1212-1218, 2003.

[19] P. W. K. Chan, S. Hussain, N. H. Ghani, J. A. Debruyne, and C. K. Liam, "The direct cost of treating bronchial asthma in a teaching hospital in Malaysia," Southeast Asian Journal of Tropical Medicine and Public Health, vol. 33, no. 3, pp. 600-603, 2002.

[20] The National Population Commission, 2006 Population and Housing Census of the Federal Republic of Nigeria. Priority Tables, vol. 1, The National Population Commission, Abuja, Nigeria, 2009.

[21] World Development Indicators, 2013, http://data.worldbank .org/data-catalog/world-developmentindicators.

[22] S. Stock, M. Redaelli, M. Luengen, G. Wendland, D. Civello, and K. W. Lauterbach, "Asthma: prevalence and cost of illness," European Respiratory Journal, vol. 25, no. 1, pp. 47-53, 2005. 


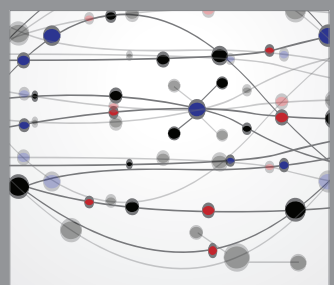

The Scientific World Journal
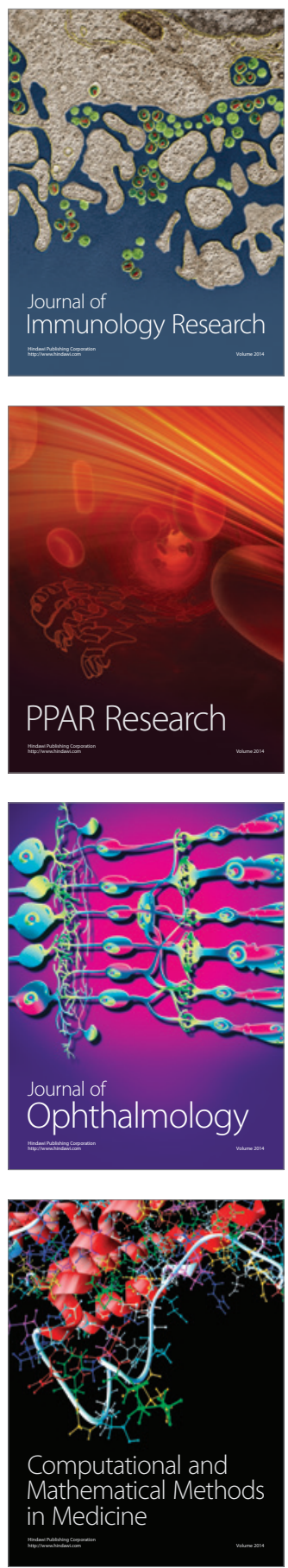

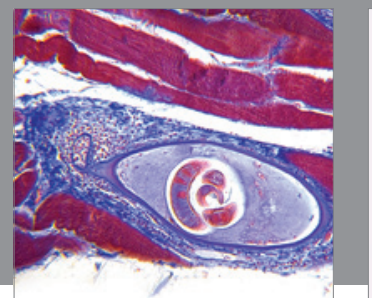

Gastroenterology

Research and Practice
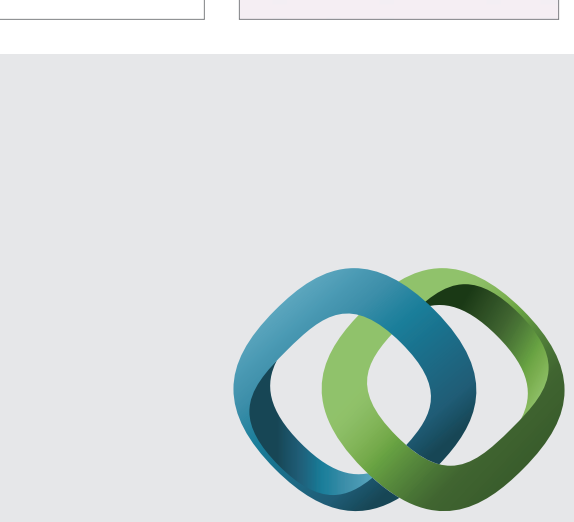

\section{Hindawi}

Submit your manuscripts at

http://www.hindawi.com
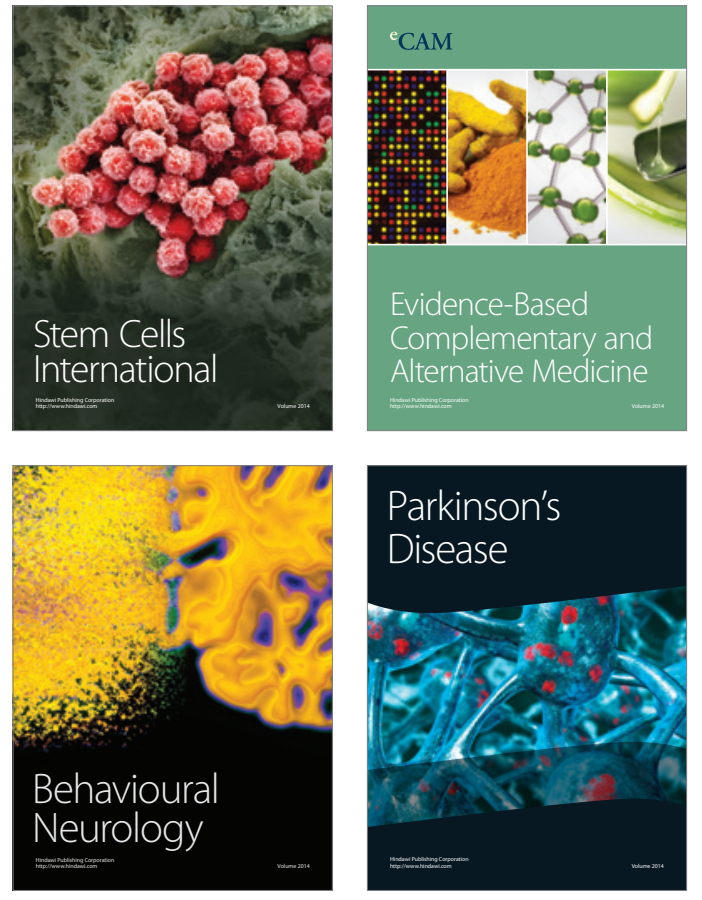
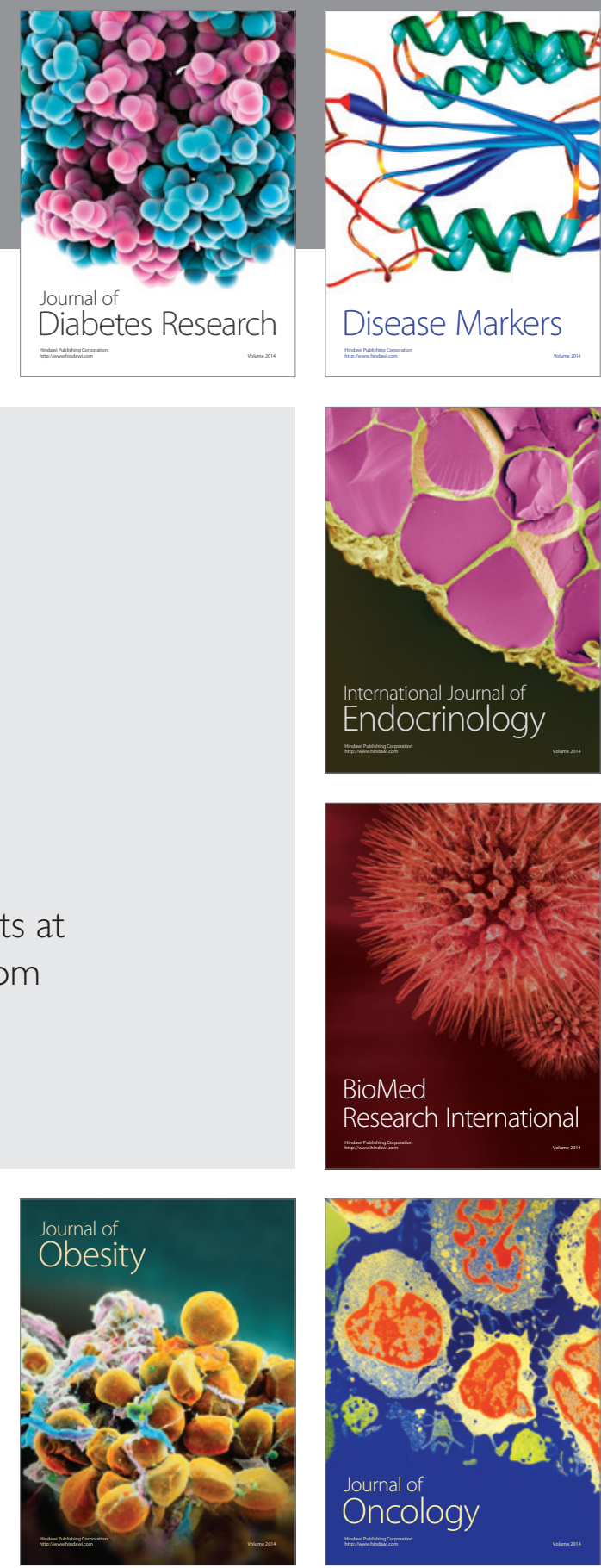

Disease Markers
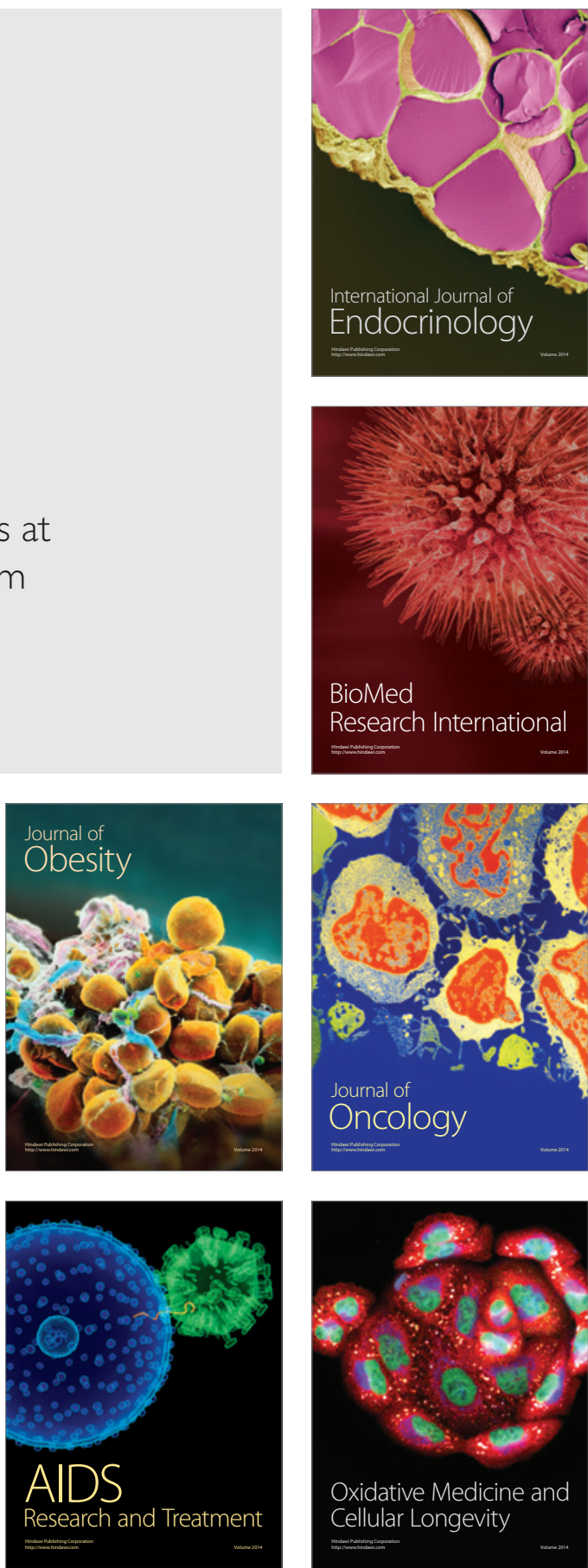